\title{
Intraventricular infusion of hyperosmolar dextran induces hydrocephalus: a novel animal model of hydrocephalus Satish Krishnamurthy*1, Jie Li ${ }^{1}$, Lonni Schultz ${ }^{2}$ and James P McAllister II ${ }^{3}$
}

Address: ${ }^{1}$ Department of Neurosurgery, Upstate Medical University, Syracuse, NY 13210, USA, ${ }^{2}$ Department of Biostatistics and Research Epidemiology, Henry Ford Hospital, 2799, West Grand Blvd, K 11, Detroit MI 48202, USA and ${ }^{3}$ Department of Neurosurgery, Division of Pediatric Neurosurgery, 175 N Medical Drive East, Salt Lake City, UT 84132, USA

Email: Satish Krishnamurthy* - krishnsa@upstate.edu; Jie Li - lij@upstate.edu; Lonni Schultz - lschult1@hfhs.org; James P McAllister - pat.mcallister@hsc.utah.edu

* Corresponding author

Published: II December 2009

Cerebrospinal Fluid Research 2009, 6:16 doi:10.1186/1743-8454-6-16
Received: 23 July 2009

Accepted: II December 2009

This article is available from: http://www.cerebrospinalfluidresearch.com/content/6/l/16

(c) 2009 Krishnamurthy et al; licensee BioMed Central Ltd.

This is an Open Access article distributed under the terms of the Creative Commons Attribution License (http://creativecommons.org/licenses/by/2.0), which permits unrestricted use, distribution, and reproduction in any medium, provided the original work is properly cited.

\begin{abstract}
Background: Popular circulation theory of hydrocephalus assumes that the brain is impermeable to cerebrospinal fluid (CSF), and is therefore incapable of absorbing the CSF accumulating within the ventricles. However, the brain parenchyma is permeable to water due to the presence of specific ion channels as well as aquaporin channels. Thus, the movement of water into and out of the ventricles may be determined by the osmotic load of the CSF. If osmotic load determines the aqueous content of CSF in this manner, it is reasonable to hypothesize that hydrocephalus may be precipitated by pathologies and/or insults that produce sustained elevations of osmotic content within the ventricles.
\end{abstract}

Methods: We investigated this hypothesis by manipulating the osmotic content of CSF and assaying the development of hydrocephalus in the rat brain. This was achieved by continuously infusing artificial CSF (negative control; group I), fibroblast growth factor (FGF2) solution (positive control; group II) and hyperosmotic dextran solutions (I0 KD and $40 \mathrm{KD}$ as experimental solutions: groups III and IV) for 12 days at $0.5 \mu \mathrm{L} / \mathrm{h}$. The osmolality of the fluid infused was 307,664 , 337 and $328 \mathrm{mOsm} / \mathrm{L}$ in Groups I, II, III and IV, respectively. Magnetic resonance imaging (MRI) was used to evaluate the ventricular volumes. Analysis of variance (ANOVA) with pairwise group comparisons was done to assess the differences in ventricular volumes among the four groups.

Results: Group I had no hydrocephalus. Group II, group III and group IV animals exhibited significant enlargement of the ventricles (hydrocephalus) compared to group I. There was no statistically significant difference in the size of the ventricles between groups II, III and IV. None of the animals with hydrocephalus had obstruction of the aqueduct or other parts of CSF pathways on MRI.

Conclusion: Infusing hyperosmolar solutions of dextran, or FGF into the ventricles chronically, resulted in ventricular enlargement. These solutions increase the osmotic load in the ventricles. Water influx (through the choroid plexus CSF secretion and/or through the brain) into the ventricles to normalize this osmotic gradient results in hydrocephalus. We need to revise the popular theory of how fluid accumulates in the ventricles at least in some forms of hydrocephalus. 


\section{Background}

Hydrocephalus is a brain disorder which manifests as an abnormal accumulation of cerebrospinal fluid (CSF) in the ventricles. It affects patients of all ages and is associated with either congenital or acquired factors, including brain trauma, infection, tumors, hemorrhage and stroke. Hydrocephalus is generally harmful to brain tissues and can result in both structural damage and cognitive impairment [1]. In the United States, hydrocephalus accounts for approximately 70,000 hospital admissions annually, with associated health care costs estimated at over two billion dollars [2].

Current strategies for diagnosing and treating hydrocephalus are based on our limited understanding of its underlying pathogenesis. Circulation theory states that CSF, produced mainly by the choroid plexus, flows through the ventricles along specific pathways to the subarachnoid space, where it is absorbed through Pacchionian granulations into venous sinuses. Obstruction of any part of this CSF circulation causes an abnormal accumulation of CSF in the ventricles resulting in hydrocephalus [3-5]. Further, popular understanding does not consider alternate pathways of CSF absorption especially through nasal lymphatics [6]. Diagnostic techniques are therefore focused primarily on detecting increases in ventricle size and blockages of CSF circulation, whereas treatment consists of medical and/or surgical interventions aimed at preventing the buildup of CSF and the associated elevation of intracranial pressure. However, hydrocephalus commonly occurs in the absence of demonstrable obstructions of CSF circulation and/or increases in intracranial pressure [7-11].

One of the fundamental assumptions of circulation theory is that the brain parenchyma is impermeable to CSF, and is therefore incapable of absorbing the CSF accumulating within the ventricles. However, the brain parenchyma is permeable to water [12]. The molecular basis of this permeability involves specific ion channels which permit water movement with ions as well as aquaporin channels, which permit the free movement of water without changing the ionic environment [13]. Aquaporin channels are membrane proteins that have an ion trap and allow movement of water without allowing movement of ions. Aquaporin 4 (AQP4) channels are found in the ependymal cells lining the lateral ventricles, and on the end feet of astrocytes that contact microvessels in the periventricular white matter and the subpial region of the cerebral cortex [14]. The distribution of AQP4 within the brain suggests that the aqueous content of CSF may be increased or decreased as water moves through the brain parenchyma between the ventricles and vascular system. Thus, the movement of water into and out of the ventricles may be determined by the osmotic load of the CSF, which is a function of the presence, type, and amount of non-diffusible macromolecules.

If osmotic load determines the aqueous content of CSF in this manner, it is reasonable to hypothesize that hydrocephalus may be precipitated by pathologies and/or insults that produce sustained elevations of osmolality within the ventricles. Our experiments were designed to test this hypothesis by experimentally manipulating the osmotic content of CSF and assaying the development of hydrocephalus in the normal rat brain. This was achieved by continuously infusing solutions of different macromolecules with different osmolarities into the lateral ventricle for 12 days, and assaying the associated enlargement of the lateral and third ventricles [15]. The resulting hydrocephalus evolved rapidly and reproducibly and was monitored using magnetic resonance imaging (MRI).

\section{Methods}

\section{Animals and experimental groups}

Adult female Sprague-Dawley rats (220-250 g; Harlan, Indianapolis, Indiana, USA) were housed in the animal care facility during a 12-h light/dark cycle throughout the protocol. All efforts were made to minimize the suffering and the number of animals used. Animal care and surgical procedures were carried out in accordance with protocol approved by the Institutional Animal Care and Use Committee at Wayne State University.

\section{Cannula implantation}

After achieving a surgical plane of anesthesia (loss of corneal, pupillary, and limb withdrawal reflexes) with a dose of $87 \mathrm{mg} / \mathrm{kg}$ ketamine plus $13 \mathrm{mg} / \mathrm{kg}$ xylazine administered intraperitoneally, rats (220-250 g body weight) were secured in a stereotaxic head frame. The eyes were moistened by the application of eye ointment. The skin was incised along the midline and the dorsal surface of the skull exposed. With a variable speed drill, a $1.5 \mathrm{~mm}$ diameter craniotomy was performed over the right cerebral hemisphere $0.9 \mathrm{~mm}$ caudal and $1.2 \mathrm{~mm}$ lateral to Bregma leaving the dura intact. A stainless steel needle (27 gauge) was advanced through the opening to a depth of $3.6 \mathrm{~mm}$ below the level of the dura at $90^{\circ}$ to the skull surface. These coordinates place the tip of needle in the frontal horn of the lateral ventricle. After slowly pulling out the needle, a customized microcatheter that was connected to an Alzet osmotic minipump was inserted through the needle track to reach the lateral ventricle. The microcatheter had the same diameter as a 27 gauge needle and was made by heating polyethylene tubing, PE 50 . The microcatheter was fixed in place by covering a piece of Surgicel (ETHICON, Inc. Somerville, USA) with cyanoacrylate adhesive (DURECT Corporation, Cupertino, USA). One or two sutures were placed with the connecting tissue around the catheter for further security. A minipump was 
then inserted into a subcutaneous pocket on the back in the mid-scapular region. The skin incision was closed with monofilament nylon suture. The Alzet osmotic minipump (Model 2002, DURECT) was primed with the solution prior to implanting. The osmolality of solutions was measured by osmometer before loading into the pump. The solution was infused at $1 \mu \mathrm{g}$ per day $(0.5 \mu \mathrm{L} / \mathrm{h})$ at a concentration of $0.083 \mu \mathrm{g} / \mu \mathrm{L}$, apart from the hypertonic saline which had a concentration of $58.44 \mu \mathrm{g} / \mu \mathrm{L}$.

After 2-3 hours, once the animal had regained consciousness and had demonstrated normal feeding and drinking behavior, it was returned to its cage and monitored periodically for the duration of the experiments. Animals were sacrificed by cardiac perfusion with saline followed by fixative buffer after the 12 days of infusion and after the final MRI scan and brain tissue was saved for further histological analysis.

\section{Lateral ventricle infusions}

Rats were randomly divided into 4 primary groups.

Group I: Artificial cerebrospinal fluid (ACSF, $n=6$ ): This group served as negative control since artificial CSF has the same osmolality as the CSF and is not expected to result in hydrocephalus. The ACSF was prepared according to a previously published method [16] and the osmolality was $307 \mathrm{mOsm} / \mathrm{L}$, measured using Micro Freezing Point Osmometer (Model 3300; Advanced Instruments, Inc., Norwood, MA, USA)

Group II: Fibroblast growth factor 2 (FGF-2, $\mathrm{n}=4$ ): This group served as a positive control. The concentration of FGF-2 (R\&D systems, Minneapolis, USA) was $0.083 \mu \mathrm{g} / \mu \mathrm{L}$ and the vehicle used was $20 \mathrm{mM}$ Tris- $\mathrm{HCl}$ and $1.0 \mathrm{M} \mathrm{NaCl}$ $(\mathrm{pH}=7.0)[15]$. The osmolality of the FGF- 2 solution was $664 \mathrm{mOsm} / \mathrm{L}$.

Group III: 10 KD dextran $(n=8)$ : This solution was hyperosmotic and was expected to result in hydrocephalus if our hypothesis was correct. The concentration of the 10 $\mathrm{KD}$ dextran in the solution was $0.083 \mu \mathrm{g} / \mu \mathrm{L}$ and the osmolality was $337 \mathrm{mOsm} / \mathrm{L}$.

Group IV: 40 KD dextran $(\mathrm{n}=8)$ : This solution was hyperosmotic and was also expected to result in hydrocephalus if our hypothesis was correct. The concentration of the 40 $\mathrm{KD}$ was $0.083 \mu \mathrm{g} / \mu \mathrm{L}$ and the osmolality was $328 \mathrm{mOsm} /$ L.

Both the protein (FGF-2) as well as the vehicle used (1 Molar saline) contributed to the osmolality of FGF-2 solution $(664 \mathrm{mOsm} / \mathrm{L})$. Based on our hypothesis, both of these hyperosmotic solutions should result in ventricular enlargement. Hence, we investigated the effect of FGF-2 and hypertonic saline separately and these groups were not included with the primary groups due to the small number of animals in each group.

Group V: FGF-2 solution with normal saline [FGF2(NS)], $(\mathrm{n}=2)$ : We used dialysis tubing (10 KD) to dialyse this FGF-2 against sterile saline over night and adjusted the concentration to $0.083 \mu \mathrm{g} / \mu \mathrm{L}$ and re-measured the osmolality, which was $326 \mathrm{mOsm} / \mathrm{L}$. We used this solution to investigate the effect of FGF-2 without its hyperosmolar vehicle.

Group VI: Hypertonic saline solution $(\mathrm{n}=3)$ : This solution was prepared at a concentration of $58.44 \mu \mathrm{g} / \mu \mathrm{L}$ and the osmolality was $910 \mathrm{mOsm} / \mathrm{L}$. This solution was expected to result in hydrocephalus if our hypothesis was correct.

\section{MRI scans and ventricular volume calculation}

Anatomical MRI images were taken in the Magnetic Resonance Research Facility at Wayne State University. MRI scans were performed after 12 days of infusion. The animal was anesthetized with ketamine and xylazine administered intraperitoneally as described previously and was placed into the MRI scanner. All MRI measurements were performed on a 4.7-T horizontal-bore magnetic resonance spectrometer (Bruker AVANCE) with an 11.6-cm-bore actively shielded gradient coil set capable of producing a magnetic field gradient of up to $250 \mathrm{mT} / \mathrm{m}$. A whole-body birdcage radiofrequency (RF) coil (inner diameter, 72 $\mathrm{mm}$ ) was used as the transmitter for homogeneous RF excitation, and a surface coil ( $30 \mathrm{~mm}$ diameter) was used as the receiver, with active RF decoupling to avoid signal interference. Coronal axial T2-weighted images (Rapid Acquisition Relaxation Enhanced or RARE sequences which minimize motion related artifacts) were acquired using the following parameters: TR $5 \mathrm{sec}$, TE(eff) $57 \mathrm{~ms}$, FOV $32 \times 32 \mathrm{~mm}^{2}, 1$ signal average, $1 \mathrm{~mm}$ slice thickness, interleaved 24 slices, TA 2 m40s.

In order to calculate the ventricular volumes, we used the semi-automated method as reported by previous studies $[17,18]$. The edge of the ventricles (region of interest) for all transverse slices was manually outlined, and the surface area was determined by counting the number of pixels enclosed by the edge automatically by the software. Segmental volume was calculated by multiplying slice area by slice thickness, and total T2-weighted MRI volume was determined by summation of the segmental volumes. Internally developed MR SPIN (Signal Processing in MR) software written in Visual C++ on the Microsoft Windows platform was used for MRI and ventricular volume calculation. Some animals died during the experiment $(\mathrm{n}=2)$ but were not included in the analysis. 


\section{Statistical methods}

ANOVA with pair-wise group comparisons was done to assess the differences in ventricular volumes among the four groups. A log transformation was used to reduce the variability across the groups. A $p$ value of less than 0.05 was considered to be significant.

\section{Results}

Animals in group I (ACSF) had no hydrocephalus. Group II (FGF2), group III (10 KD) and group IV (40 KD) animals exhibited significant enlargement of the ventricles (hydrocephalus) compared to group I (I vs II $p=0.002$, I vs III $p=0.009$, and I vs IV $p=0.023$; Figures 1 and 2 ). There was no statistically significant difference in the size of the ventricles between any of the groups II, III and IV. The ventricular volumes for animals in all groups are listed in the Table 1 . The osmolality of the fluid infused was $307 \mathrm{mOsm} / \mathrm{L}(\mathrm{Group} \mathrm{I}: \mathrm{ACSF}$ ), $337 \mathrm{mOsm} / \mathrm{L}$ (Group III: $10 \mathrm{KD}$ )and $328 \mathrm{mOsm} / \mathrm{L}$ (Group IV; $40 \mathrm{KD}$ ). Additional two sample t-tests were done to compare group I (ACSF) to group V (FGF2 with normal saline) and VI (Hypertonic saline). Group V FGF-2-infused animals had significant hydrocephalus compared to Group I (mean (SD) 42.4 (1.5) vs $23.6(8.6) \mu \mathrm{L} ; p=0.04)$. Group VI hypertonic saline-infused animals also showed a trend to induced hydrocephalus when compared to Group I (mean (SD) 33.9 (3.9) $\mu \mathrm{L}$ vs $23.6(8.6) \mu \mathrm{L}$ ) although it was not significant.
Ventriculomegaly was moderate and was consistent throughout the lateral and the third ventricles but not apparent in the fourth ventricle. The ventricular enlargement was asymmetric in some animals with the larger ventricle on the side of infusion. There were two animals which had ventricular size that were much larger than the rest of the group. One of them was in the ACSF group and the other was in the $10 \mathrm{KD}$ group. This was probably due to variability in the size of the ventricles prior to infusion, rather than an effect of the infusing solutions. We do not know the exact reason in this set of experiments as we did not perform MRI scans prior to infusing the solutions. However, in the experiments that we have done since, we have seen such variability in the pre-infusion scans. None of the animals with hydrocephalus had obstruction of the aqueduct or other parts of CSF pathways on MRI (Figure 3).

\section{Discussion}

We hypothesized that osmotic load in the ventricles determines the aqueous content of CSF. Our experiments were designed to test this hypothesis by experimentally manipulating the osmotic load of CSF and assaying the development of hydrocephalus in the normal rat brain. This was achieved by continuously infusing hyperosmolar solutions of FGF-2, $10 \mathrm{KD}$ and $40 \mathrm{KD}$ dextrans into the lateral ventricle for 12 days. There was significant enlargement of ventricles on the MRI in all these groups compared to

Table I: Ventricular volumes $(\mu L)$ in animals for the different infusion groups.

\begin{tabular}{|c|c|c|c|c|c|c|}
\hline & $\begin{array}{l}\text { Group I } \\
\text { ACSF }\end{array}$ & $\begin{array}{c}\text { Group II } \\
\text { FGF2 }\end{array}$ & $\begin{array}{l}\text { Group III } \\
\text { I0 KD } \\
\text { Dextran }\end{array}$ & $\begin{array}{c}\text { Group IV } \\
40 \text { KD } \\
\text { Dextran }\end{array}$ & $\begin{array}{c}\text { Group V } \\
\text { FGF2 (NS) }\end{array}$ & $\begin{array}{c}\text { Group VI } \\
\text { Hypertonic Saline }\end{array}$ \\
\hline & 17.95 & 51.52 & 40.82 & 38.02 & 41.40 & 29.64 \\
\hline & 16.43 & 33.17 & 43.55 & 34.60 & 43.46 & 37.29 \\
\hline & 25.85 & 43.16 & 31.18 & 20.33 & & 34.71 \\
\hline & 39.58 & 34.82 & 35.74 & 25.95 & & \\
\hline & 18.39 & & 30.77 & 38.10 & & \\
\hline & 23.48 & & 41.78 & 39.00 & & \\
\hline & & & 96.54 & 36.67 & & \\
\hline & & & 24.81 & 35.53 & & \\
\hline Mean & 23.61 & 40.67 & 43.15 & 33.53 & 42.43 & 33.88 \\
\hline Median & 20.94 & 38.99 & 38.28 & 36.10 & 42.43 & 34.71 \\
\hline SD & 8.61 & 8.45 & 22.51 & 6.74 & 1.46 & 3.89 \\
\hline
\end{tabular}



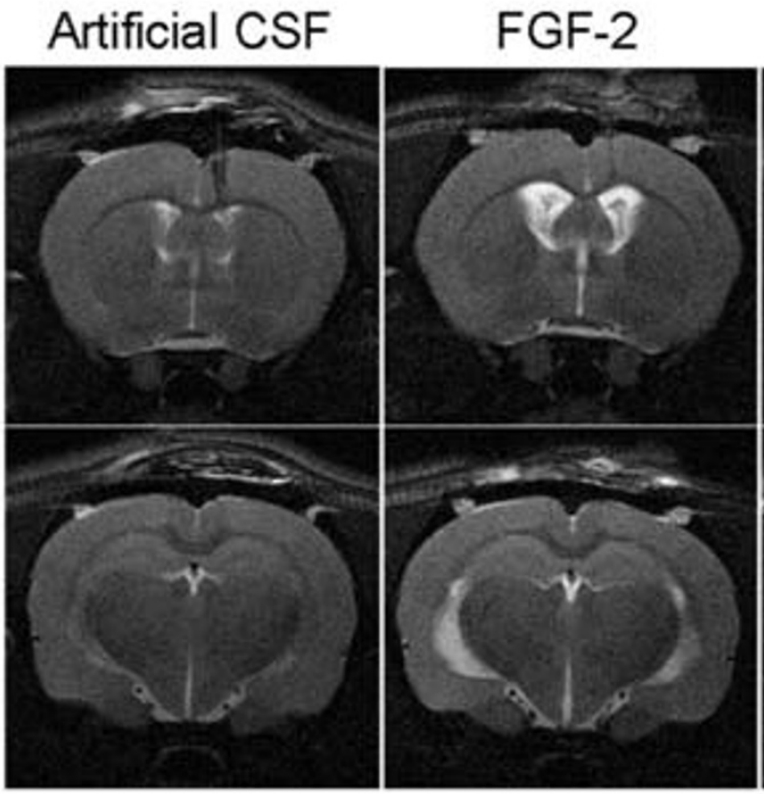
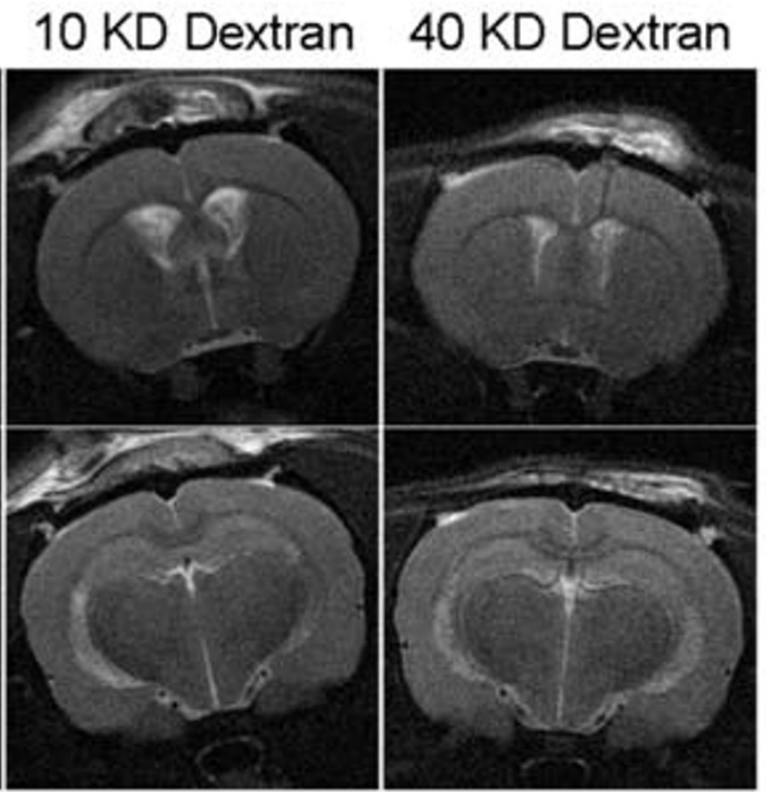

\section{Figure I}

Representative examples of MRI images of animals after I 2 days of infusion of artificial CSF (negative control), FGF-2 (positive control), I 0 KD and 40 KD dextran (experimental) solutions. Note that the ventriculomegaly produced by FGF-2, 10 KD and 40 KD dextrans were similar.

infusing iso-osmolar ACSF. The MRI scan did not show any obstruction of the aqueduct or other parts of the CSF pathways on MRI.

Popular CSF circulation theory explaining the genesis of hydrocephalus fails to consider various clinical observations and also fails to consider some experimental findings [19-27]. In addition, current diagnostic and therapeutic strategies that are based on this framework of thinking fall short in helping to treat patients with hydrocephalus effectively. One such clinical example is the current algorithm used for diagnosing hydrocephalus. Hydrocephalus is diagnosed by computed tomography (CT) examination or MRI scan and correlated with clinical symptoms, to determine treatment. Although radiological diagnosis is effective for most patients, there are several situations that pose problems. The size of the ventricles alone does not determine whether a patient has symptoms of hydrocephalus [28]. Further, ventricle size has no relationship to the pressure inside the ventricle; examples include pseudotumor cerebri (small ventricles with high pressure), normal pressure hydrocephalus (NPH, large ventricles with normal pressure), and stiff non-compliant ventricles (small ventricles with low, normal or high pressures). Pressure-volume relationships have been used to evaluate the need for treatment of hydrocephalus from different conditions $[29,30]$. Intracranial pressure record- ing is more helpful but does not always predict who will benefit from surgery to relieve hydrocephalus [31]. In fact, a recent paper on treatment of NPH highlights the limitations of current diagnostic methods in diagnosing hydrocephalus and predicting outcomes following surgery [32]. Clinical practice becomes subjective and varies widely as a consequence of uncertainties in interpretation of clinical and radiological data even among experts in the field. Clinical decision making would definitely benefit from a better understanding of pathophysiology of hydrocephalus. This is the motivation for revisiting the current concept of pathogenesis of hydrocephalus.

There is circumstantial evidence to the role played by the osmotic gradients. It is well known clinically that osmotic gradients play a role in the brain tissues (excluding the ventricular space) in normal and abnormal states. For example, in brain edema, osmotic diuretics like mannitol are used intravenously to draw water away from the extracellular space of the brain. Brain swelling can result in conditions where there is hyponatremia which permits water movement into the tissues of the brain resulting in brain edema [33]. Clinically, high protein levels in the CSF have been detected in hydrocephalus irrespective of radiologic obstruction to the CSF pathways. Higher levels of thrombopoietin [34], ferritin [35], nerve growth factor[36], chondroitin sulfate proteoglycan [37] transform- 


\section{Ventricular Volumes In Different Groups}

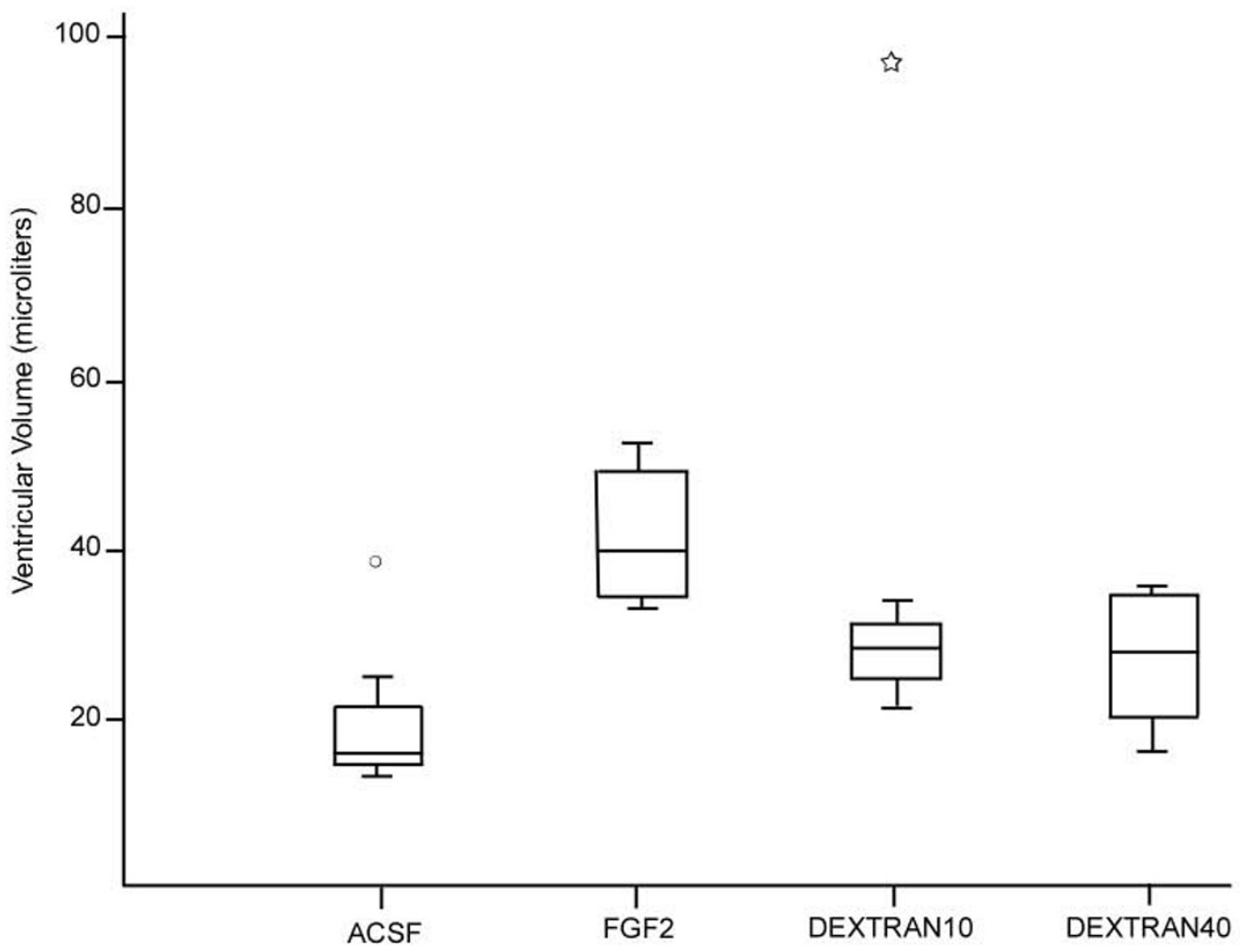

\section{Figure 2}

Box plot showing the ventricular volumes in $\mu \mathbf{L}$ for the different infusion groups. The center line of the boxplot is the median value with the upper and the lower margins of the box representing the upper quartile $\left(75^{\text {th }}\right.$ percentile) and the lower quartile representing ( $25^{\text {th }}$ percentile). The upper and lower fences represent the value equal to I.5 times the difference between the lower and upper quartiles (interquartile ratio). The outliers are represented by a mark outside the box plot. Note that all the infusions resulted in enlarged ventricles except for ACSF, and were significantly different from the ACSF group (I vs II $p=0.002$, I vs III $p=0.009$, and I vs IV $p=0.023$ ). Note: Two outlying symbols represent ventricular size of animals in the ACSF and 10 KD dextran group that were much larger than the rest of the group.

ing growth factor $\beta 1[38,39]$, transforming growth factor $\beta 2$ [37], S-100 protein $[40,41]$, and vascular endothelial growth factor [42] have been found in ventricular CSF in patients with hydrocephalus resulting from intraventricular hemorrhage. Even in patients without any intraventricular blood, elevated proteins have been found in ventricular CSF in hydrocephalus resulting from intracranial schwannomas [7], a few cases of spinal schwannomas $[8,9]$, and in about $4 \%$ of patients with Guillain-Barre' syndrome $[10,11]$. In a review of potential biomarkers for chronic hydrocephalus, Tarnaris et al concluded that tumor necrosis factor, tau protein, lactate, sulfatide and neurofilament triple protein are elevated in chronic hydrocephalus to make them the most promising CSF markers [43]. In addition to proteins, increased levels of lactate $[43,44]$ and lactic dehydrogenase (LDH) [45] have been found in hydrocephalus. Increased levels of ions (calcium, magnesium and phosphate) found in congenital hydrocephalus correlated with elevated protein levels [46]. An extensive summary of changes in the composition of CSF in hydrocephalus was reviewed by Del Bigio [47]. It is unclear whether these changes in proteins or peptides are a cause or a consequence of hydrocephalus.

The importance of the role played by excess macromolecules in the ventricle in hydrocephalus is strengthened by 

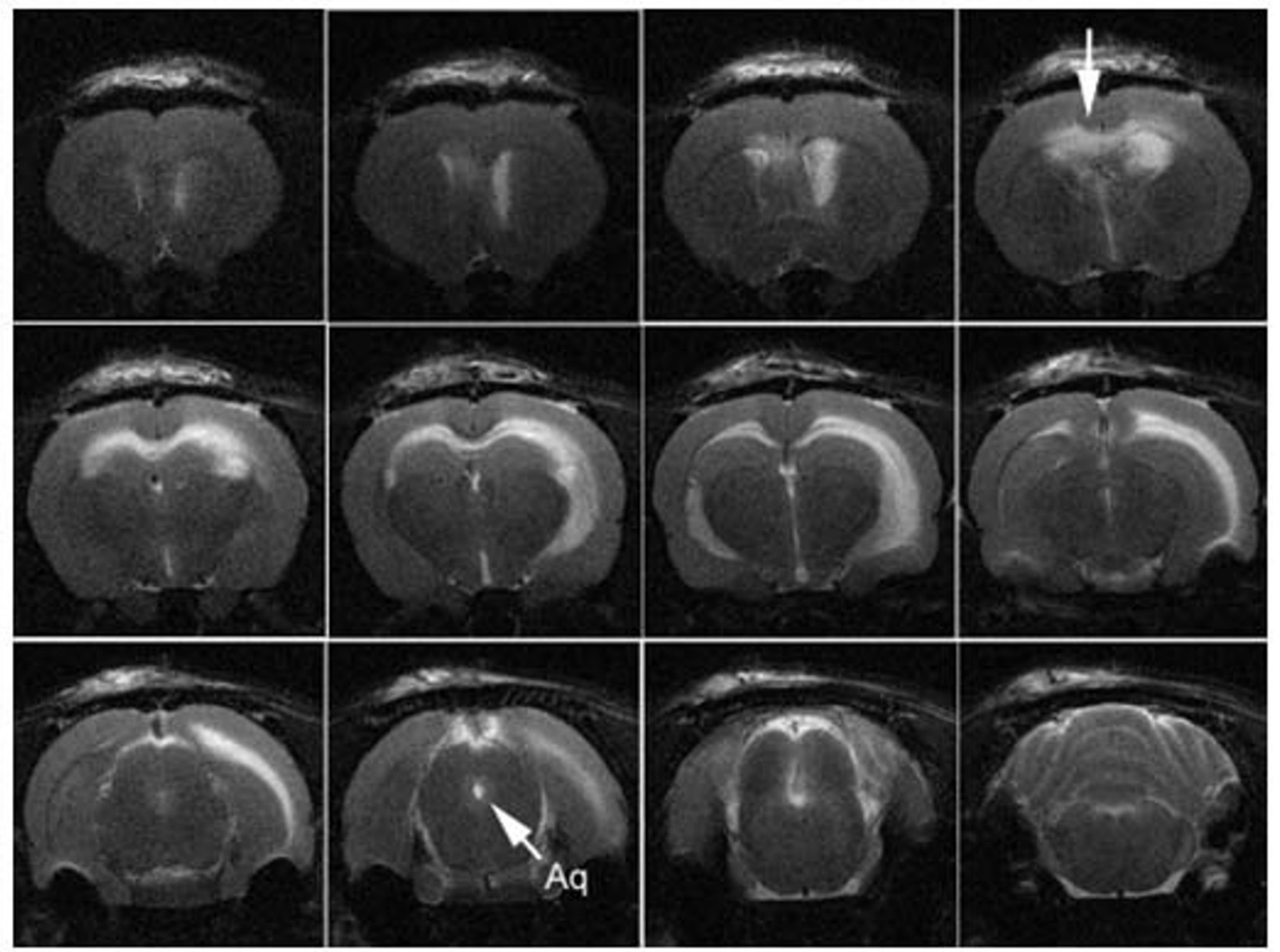

\section{Figure 3}

T2-weighted MRI of animal with hydrocephalus induced by I0 KD dextran. Note the periventricular edema (arrow top row last figure from the left) in the corpus callosum and external capsule and the patent cerebral aqueduct (arrow labeled $\mathrm{Aq})$. Note that the ventricular enlargement was asymmetric with the larger ventricle on the side of infusion.

the relief of hydrocephalus in situations that decrease the amount of macromolecules in the CSF. Decreasing levels of protein and blood products with removal of CSF through an Ommaya ventricular reservoir is associated with resolution of hydrocephalus in about $17 \%$ of neonates with intraventricular hemorrhage $[48,49]$. The elimination of blood and blood products decreases the incidence of hydrocephalus due to aneurysmal subarachnoid hemorrhage [50]. One explanation of how elimination of macromolecules results in relief of hydrocephalus is the decrease in the osmotic load in addition to reduction of their biological effect on the brain and CSF secretion.

In addition to the clinical evidence, some experimental evidence suggests that osmolality plays a role in the gene- sis of hydrocephalus, although there have been no studies focusing primarily on this mechanism. Wald et al found that increasing the ventricular fluid osmolality in a perfusate increased the volume of CSF produced [51] and increasing the serum osmolality decreased CSF production in normal cats [52]. These experiments led the authors to conclude that CSF production is influenced by the osmotic gradient between the serum and the ventricular CSF. In other experiments, infusion of protein (FGF-2) into the lateral ventricles of experimental animals caused dilatation of the ventricles [15].

The strongest argument against circulation theory comes from experiments focusing on the development of ventricles in embryos. It is well known that brain ventricles are a highly conserved system of cavities that form early dur- 
ing brain morphogenesis in vertebrates and are required for normal brain function [53]. In a series of elegantly done experiments, Lowery and Sive were able to show that initial ventricle expansion occurs independently of circulation and is related to cellular proliferation in zebrafish embryos [54]. Although onset of circulation contributed to continued expansion of the ventricles, ventricular expansion occurred in silent heart mutant zebrafish embryos which do not have a beating heart [54].

The neural tube is a single cell layer tube that is permeable to water. Expansion of this tube involves changes in the osmolality of the neural tube fluid. As another example, Alonso et al, during an investigation of the underlying mechanism of neural tube expansion in chick embryos found that increasing the neural tube fluid osmolality resulted in hydrocephalus [53]. These studies clearly suggest that osmolality of the fluid in the ventricles plays a role in the regulation of the size of the ventricles at least in the embryonic stage.

\section{Conclusion}

Continuous infusion of large molecules such as FGF and dextran into the lateral ventricles resulted in ventricular enlargement (hydrocephalus). It is concluded that increasing the osmotic load results in water influx (through choroid plexus CSF secretion and/or through the brain) into the ventricles to normalize the osmotic gradient. The popular theory of how fluid accumulates in the ventricles may need to be revised, at least in some forms of hydrocephalus. It is important to note that our concept does not affect the pressure, volume and compliance changes seen in hydrocephalus.

\section{Competing interests}

The authors declare that they have no competing interests.

\section{Authors' contributions}

SK designed the study, was primary investigator and primary author. J L performed the experiments, obtained the MRI scan data, assisted in designing the study and writing the article. P M helped design and fund the study and assisted in writing the article. LS performed statistical analysis and helped write the article.

All authors have read and approved the final version of the manuscript.

\section{Acknowledgements}

We would like to thank the Henry Ford Hospital Department of Neurosurgery for their help and support in providing the funding and time to perform this research and to acknowledge the help and support from the Wayne State University Department of Neurosurgery, for providing the research facilities.

\section{References}

I. Sainte-Rose C: Hydrocephalus in childhood. In Neurological Surgery 4th edition. Edited by: Youmans JR. Philadelphia: WB Saunders; 1996:890-922.

2. Simon TD, Riva-Cambrin J, Srivastava R, Bratton SL, Dean JM, Kestle JRW: Hospital care for children with hydrocephalus in the United States: utilization, charges, comorbidities, and deaths. J Neurosurg - Pediatr 2008, I:|3|-|37.

3. Rekate HL: Hydrocephalus in children. In Neurological Surgery 5 th edition. Edited by: Youmans JR. Philadelphia: WB Saunders; 2004:3387-3404.

4. McAllister JP II, Chovan P: Neonatal hydrocephalus: mechanisms and consequences. In Neurosurg Clin N America, Neurosurgery of the Neonate Edited by: Frim DM, Madsen JR. Philadelphia: W.B. Saunders; 1998:73-93.

5. Del Bigio MR, McAllister JP II: Pathophysiology of hydrocephalus. In Pediatric Neurosurgery Edited by: Choux M, DiRocco CE, Hockley AD, Walker ML. London: Churchill Livingstone; 1999:2 I7-236.

6. Johnston M, Papaiconomou C: Cerebrospinal fluid transport: a lymphatic perspective. News Physiol Sci 2002, I 7:227-230.

7. Bloch J, Vernet O, Aube M, Villemure JG: Non-obstructive hydrocephalus associated with intracranial schwannomas: hyperproteinorrhachia as an etiopathological factor? Acta Neurochir (Wien 2003, 145:73-78.

8. Crivelli G, Fachinetti P: Lumbar neurinoma associated with hydrocephalus. Case report. J Neurol Sci 1993, 37:179-182.

9. Ohta K, Gotoh F, Amando T, Obary K: Normal pressure hydrocephalus associated with cauda equina neurinoma. Ann Neurol 1990, 27:441-443.

10. Ersahin Y, Mutler S, Yurtseven T: Hydrocephalus in GuillainBarre' syndrome. Clin Neurol Neurosurg 1995, 97:253-255.

II. Ropper AH, Marmarou A: Mechanism of pseudotumor in Guillain-Barre' syndrome. Arch Neurol 1984, 41:259-26I.

12. Gato A, Moro JA, Alonso MI, Pastor JF, Represa JJ, Barbosa E: Chondroitin sulfate proteoglycan and embryonic brain enlargement in the chick. Anat Embryol 1993, 188:101-106.

13. Agre P: Aquaporin water channels. Biosci Rep 2004, 24: I $27-163$.

14. Agre P, Nielsen S, Ottersen OP: Towards a molecular understanding of water homeostasis in the brain. Neuroscience 2004, I 2:849-850.

15. Johanson CE, Szmydynger-Chobodska J, Chobodski A, Baird A, McMillan P, Stopa EG: Altered formation and bulk absorption of cerebrospinal fluid in FGF-2 induced hydrocephalus. Am J Physiol 1999, 277:R263-R27I.

16. Chodobski $A$, Segal MB: In vivo techniques used in Blood-CSF barrier research: Measurement of CSF formation. In The Blood-Cerebrospinal Fluid Barrier Edited by: Zheng W, Chodobska A. Boca Raton: Chapman and Hall; 2005:598-599.

17. Caviness VS Jr, Lange NT, Makris N, Herbert MR, Kennedy DN: MRI based brain volumetrics: emergence of a developmental brain science. Brain Dev 1999, 21:289-295.

18. Jacobsen LK, Geidd JN, Berquin PC, Krain AL, Hamburger SD, Kumra S, Rappaport JL: Quantitative morphology of the cerebellum and fourth ventricle in childhood-onset schizophrenia. $\mathrm{Am} J$ Psychiatry 1997, I 54:1663-1669.

19. Maurizi CP: A cycle of cerebrospinal fluid: supporting evidence and theoretical considerations. Med Hypoth 2000, 54:4 I 7-422.

20. Greitz D: Cerebrospinal fluid circulation and associated intracranial dynamics. A radiologic investigation using $M R$ imaging and radionuclide cisternography. Acta Radiol Suppl 1993, 386: I-23.

21. Czosnyka M, Czosnyka Z, Momjian S, Pickard JD: Cerebrospinal fluid dynamics. Topical Review. Physiol Meas 2004, 25:R5I-R76.

22. Ghersi-Egea JF, Finnegan W, Chen JL, Fenstermacher JD: Rapid distribution of intraventricularly administered sucrose into cerebrospinal fluid cisterns via subarachnoid velae in rat. Neuroscience 1996, 75:127|-1288.

23. Davson $\mathrm{H}$ : Formation and drainage of the cerebrospinal fluid. In Hydrocephalus Edited by: Shapiro K, Marmarou A, Portnoy HD. New York: Raven Press; 1984:3-40.

24. Uno M, Takano T, Yamano T, Shimada M: Age-dependent susceptibility in mumps associated hydrocephalus: neuropathologic features and brain barriers. Acta Neuropathol 1997, 94:207-2 I5.

25. Jacobson EE, Fletcher DF, Morgan MK, Johnston IH: Fluid dynamics of cerebral aqueduct. Pediatr Neurosurg 1996, 24:229-236. 
26. Shapiro K, Kohn IJ, Takei F, Zee C: Progressive ventricular enlargement in cats in the absence of transmantle pressure gradients. J Neurosurg 1987, 67:88-92.

27. Penn RD, Lee MC, Linninger AA, Miesel K, Lu SN, Stylos L: Pressure gradients in the brain in an experimental model of hydrocephalus. J Neurosurg 2005, 102:1069-1075.

28. Barnes NP, Jones SJ, Hayward RD, Harkness WJ, Thompson D: Ventriculoperitoneal shunt block: what are the best predictive clinical indicators? Arch Dis Child 2002, 87:198-20।.

29. Tans JT, Poortvliet DC: Intracranial volume-pressure relationship in man. Part I: Calculation of the pressure-volume index. J Neurosurg 1982, 56:524-528.

30. Tans JT, Poortvliet DC: Intracranial volume-pressure relationship in man. Part 2: Clinical significance of the pressure volume index. J Neurosurg 1983, 59:810-816.

31. Eide PK: Quantitative analysis of continuous intracranial pressure recordings in symptomatic patients with extracranial shunts. I Neurol Neurosurg Psychiat 2003, 74:23 I-237.

32. Hebb AO, Cusimano MD: Idiopathic normal pressure hydrocephalus: A systematic review of diagnosis and outcome. Neurosurgery 200I, 49: I I66-II86.

33. Trinh-Trang-Tan MM, Cartron JP, Bankir L: Molecular basis for the dialysis disequilibrium syndrome: altered aquaporin and urea transporter expression in the brain. Nephrol Dial Transplant 2005, 20: 1984-1988.

34. Reinhold A, Zhang J, Gessner R, Felderhoff-Mueser U, Obladen M, Dame C: High thrombopoietin concentrations in the cerebrospinal fluid of neonates with sepsis and intraventricular hemorrhage may contribute to brain damage. J Interferon Cytokine Res 2007, 27:137-145

35. Suzuki H, Muramatsu M, Tanaka K, Fujiwara H, Kojima T, Taki W Cerebrospinal fluid ferritin in chronic hydrocephalus after aneurysmal subarachnoid hemorrhage. J Neurol 2006 253: I I70- II76.

36. Mashayekhi F, Salehi Z: Expression of nerve growth factor in cerebrospinal fluid of congenital hydrocephalic and normal children. Eur J Neurol 2005, I 2:632-637.

37. Chow LC, Soliman A, Zandian M, Danielpour M, Krueger RC Jr: Accumulation of transforming growth factor-beta2 and nitrated chondroitin sulfate proteoglycans in cerebrospinal fluid correlates with poor neurologic outcome in preterm hydrocephalus. Biol Neonate 2005, 88: I-I I.

38. Flood C, Akinwunmi J, Lagord C, Daniel M, Berry M, Jackowski A, Logan A: TGF $\beta I$ in the CSF of patients with subarachnoid hemorrhage: titers derived from exogenous and endogenous sources. J Cereb Blood Flow Metab 200I, 2 I: I57-I62.

39. Whitelaw A, Christie S, Pople I: TGF $\beta$ I: a possible signal molecule for posthemorrhagic hydrocephalus? Pediatr Res 1999 46:576-580

40. Beems T, Simons KS, van Geel WJA, de Reus HPM, Vos PE, Verbeek MM: Serum and CSF-concentrations of brain specific proteins in hydrocephalus. Acta Neurochir (Wien) 2003, I 45:37-43.

4I. Sendrowski K, Sobaniec W, Sobaniec-Lotowska ME, Lewczuk PS: S100 protein as marker of the blood-brain barrier disruption in children with internal hydrocephalus and epilepsy--a preliminary study. Roczniki Akademii Medycznej W Bialymstoku 2004, 49(Suppl I):236-238.

42. Heep A, Stoffel-Wagner B, Bartmann P, Benseler S, Schaller C, Groneck P, Obladen M, Felderhoff-Mueser U: Vascular endothelia growth factor and transforming growth factor-betal are highly expressed in the cerebrospinal fluid of premature infants with posthemorrhagic hydrocephalus. Pediatric Res 2004, 56:768-774

43. Tarnaris A, Watkins LD, Kitchen ND: Biomarkers in chronic adult hydrocephalus. Cerebrospinal Fluid Res 2006, 3: I I

44. Nooijen PT, Schoonderwaldt HC, Wevers RA, Hommes OR, Lamers $\mathrm{KJ}$ : Neuronspecific enolase, $\mathrm{S}-100$ protein, myelin basic protein and lactate in CSF in dementia. Dement Geriatr Cogn Disord 1997, 8:169-173.

45. Nussinovitch M, Volovitz B, Finkelstein Y, Amir J, Harel D: Lactic dehydrogenase isoenzymes in cerebrospinal fluid associated with hydrocephalus. Acta Paediatr 2001, 90:972-974.

46. Cerda M, Manterola A, Ponce S, Basauri L: Electrolyte levels in the CSF of children with non-tumoral hydrocephalus. Childs Nerv Syst $1985,6: 306-311$.
47. Del Bigio MR: Hydrocephalus-induced changes in the composition of cerebrospinal fluid. Neurosurgery 1989, 25:416-423.

48. Whitelaw A, Pople I, Cherian S, Evans D, Thoresen M: Phase I tria of prevention of hydrocephalus after intraventricular hemorrhage in newborn infants by drainage, irrigation and fibrinolytic therapy. Pediatrics 2003, I I I:759-765.

49. Perrata P, Regazzi P, Carlino CF, Gaglini P, Cinalli G: The role of Ommaya reservoir and endoscopic third ventriculostomy in the management of post hemorrhagic hydrocephalus in prematurity. Childs Nerv Syst 2007, 23:765-77I.

50. Brinker T, Seifert V, Dietz H: Subacute hydrocephalus after experimental subarachnoid hemorrhage: its prevention by intrathecal fibrinolysis with recombinant tissue plasminogen activator. Neurosurgery 1992, 31:306-3II.

51. Wald A, Hochwald GM, Malhan C: The effects of ventricular fluid osmolality on bulk flow of nascent fluid into the cerebral ventricles of cats. Exp Brain Res 1976, 25:157-167.

52. DiMattio J, Hochwald GM, Malhan C, Wald A: Effects of changes in serum osmolality on bulk flow of fluid into cerebral ventricles and on brain water content. Pflugers Arch 1975 , 359:253-264.

53. Alonso MI, Gato A, Moro JA, Barbosa E: Disruption of proteoglycans in neural tube fluid by $\beta-D$ xyloside alters brain enlargement in chick embryos. Anat Rec 1998, 252:499-508.

54. Lowery LA, Sive H: Initial formation of zebrafish ventricles occurs independently of circulation and requires nagie oko and snakehead/atplala.I gene products. Development 2005, I 32:2057-2067.

Publish with Biomed Central and every scientist can read your work free of charge

"BioMed Central will be the most significant development for disseminating the results of biomedical research in our lifetime. "

Sir Paul Nurse, Cancer Research UK

Your research papers will be:

- available free of charge to the entire biomedical community

- peer reviewed and published immediately upon acceptance

- cited in PubMed and archived on PubMed Central

- yours - you keep the copyright
BioMedcentral 